\title{
Social Innovation through Urban Regeneration - A Local Model
}

Andreea-Alexandra ANECHITEI ${ }^{1}$

\begin{abstract}
This paper introduces the analytic context of a social innovation model analyzed through a local urban regeneration process. Urban regeneration is the bringing to life of urban areas with the cooperative effort of municipalities, owners and other stakeholders involved in improving living conditions, enhancing the quality of the environment and the social climate, and strengthening the local economy. The main question is: Can an urban regeneration project be considered social innovation? To answer that, the purpose of this article is the analysis of an urban regeneration project as a social innovation one. The paper employs content analysis exploring a study case within a pilot urban regeneration project. The paper findings suggest that the main purpose of social innovation in the urban regeneration of the Ferentari neighborhood is not the profit: social innovation consists of innovative activities and services motivated by the purpose of responding to a social need, disseminated through organizations, individuals or enterprises whose main purpose is social.
\end{abstract}

Keywords: social innovation, public sector, social model, local administration, urban regeneration

JEL classification: $\mathrm{O} 35, \mathrm{O} 47$

DOI: $10.24818 /$ RMCI.2018.3.244

\section{Introduction}

The concept of innovation is almost new to local authorities from the public sector. In the public administration innovation can be a frequent issue, but could also be considered an inspiring concept due to its radical change promises (Mulgan, 2006), the will of innovating the public sector was presented several times throughout history, being linked occasionally to change programs so it satisfies the introduction of new ideologies (management and governance), the budget reductions or the implementation of new technologies.

Innovation is a periodic issue in public administration and is considered necessary in order to improve efficiency, effectiveness and authenticity. Innovation inspires the population and policy makers ensuring a radical change, but how can the change be generated in a system where all things seem stagnant, as the public sector? This paper will analyze a theoretical pilot program of urban regeneration,

\footnotetext{
${ }^{1}$ The Bucharest University of Economic Studies, Romania, anechitei.andreea@gmail.com, 0746099410
} 
applicable to the Ferentari neighborhood from district 5 of Bucharest Romania, considered to be a socially innovative one.

How the public sector can do social innovation through urban regeneration? The objective of this paper is the analysis of the urban regeneration project as a social innovation one. Specifically, the urban regeneration process addresses sectors such as infrastructure, urban mobility, urban public spaces, employment, education, access to services, community and public image. It aims to solve the urban problems of the area and to find a long-term improvement of the economical, physical, social, and environmental conditions for the neighborhood and implicitly for the sector.

\section{Literature review}

\section{Social innovation and urban regeneration in the public sector}

Literature suggests that social innovations focused on the environment differ mainly from social innovations centered on the individual by the target of the changes they intend to bring about (Adams and Hess, 2008). Environmentallyoriented social innovations aim to develop a specific territory in order to improve the quality of life. The review of the literature reveals two (2) approaches: the development approach (territory) and the consumption approach. This study contributes to the literature on social innovation in the public sector by looking at the social innovation orientated to groups, to the environment through some practices of urban regeneration process ready to be implemented in a marginalized, poor and socially isolated urban area (Walters, 2001).

Social innovation is about developing new responses to new or undersatisfied social needs under current market conditions and social policies, involving the participation and cooperation of relevant actors. These innovations concern the product or service as well as the organization and distribution in areas such as aging, early childhood, housing, health, the fight against poverty, exclusion, discrimination.

Social innovation is a new structural solution to a social problem, a solution that produces a social change in the sense of an improvement in the existing situation and an increase in the quality of life for groups of individuals, communities and society as a whole, a solution that has been disseminated and adopted and whose main purpose is not the profit of a group of people. At the macroeconomic level, innovation is recognized as the dominant factor in the economic growth and trade specialization of countries. In particular, it is considered to be indispensable in saving the Western industry. Radical innovations shape the great changes of the world and progressive innovations are fueling economic change. In general, social innovation is a "new response" to a social situation deemed unsatisfactory, a situation likely to manifest itself in all sectors of society. Social innovation responds to this because it addresses the well-being of individuals and / or communities. It is defined in action and sustainable change. It 
aims to develop the individual, the environment or the company. Social innovation can be seen as a collective process of learning and creation of knowledge.

According to Cooperrider and Pasmore (1991), Taylor (1970) was the first researcher to use the term "social innovation". The literature reveals, however, that at the same time, Gabor (1970) looked at the issue from a developmental perspective (territory). According to this, social innovation refers to new ways of doing things for the explicit purpose of addressing social needs, such as poverty and delinquency and the emergence of social innovations is the result of the creation of multidisciplinary teams. It seems therefore that the object of social innovation, is the solution to the problem and refers exclusively to what is being implemented.

Other researchers seem to have adopted a developmental or territorial approach. First, Gabor (1970) considers social innovation as an instrument for combating urbanization, pollution, crime and corruption, economic inequality and violence. In the development of a "new social arrangement", "a new equilibrium", social innovations take the form of technical innovations (ex: electric train) or legislation (ex: the environment). Social innovations respond precisely because of the positive social consequences that they entail. In Gabor (1970) the conditions of production and implementation as well as the distinctive characteristics of social innovations are evacuated from the problematization. Because it refers to the "transformation of the structure of consumption" of a society, social innovation "structures lifestyles and types of life" (Langlois, 2002). Social innovation therefore seems to be intimately linked to "social change" and could, if necessary, prove to be very similar to that of "social transformation". In my view, withdrawal into the sphere of private life to meet personal needs, coupled with the breakdown of the family, could be considered one of the manifestations of the progressive breakdown of the social bond.

Urban regeneration is defined as "comprehensive and integrated vision and action which leads to the resolution of urban problems and which seeks to bring about a lasting improvement in the economic, physical, social and environmental condition of an area that has been subject to change" (Roberts, 2000, p.34).

According to Sassen (2007), urban regeneration must respond to changing conditions in cities that represent new markets for new groups of people through new economic concentrations. It is dominated by real estate development and economic strengths, representing a difficult field to be included as an element in a social policy. Improving social care services in poor neighborhoods along with the responsibility of local communities is part of a process of social regeneration.

As mentioned by Porter and Shaw (2013), urban regeneration projects must involve all local stakeholders interested in reforming a city from the first stages of creation to the final plan. This participatory level (Evans, 2009) considers that classical telematics of economic, social and cultural development are again fully expanded by the contribution of local actors to urban planning in a larger and richer perspective. 
And from this point of view, innovation as a periodic issue in public administration is considered necessary in order to improve efficiency, effectiveness and authenticity. Innovation inspires the population and policy makers ensuring a radical change, but how can the change be generated in a system where all the things seem stagnant, as the public sector? On the other hand, innovation is a risky process itself, because the results are almost always unknown. While Drucker (1985) highlights the importance of innovation and entrepreneurship through the development of organizations in the long term, goal-oriented and a systematic perspective on the use of resources (knowledge, people and funds), we find barriers that prevent the process. In the public sector there is a negative attitude towards risk and risk-taking given that political cultures and bureaucracy are known as riskavoiding and given that focus on short-term political grows and forces (Borins 2008; Kelman, 2008, Albury, 2005). The current policy is characterized by a shortterm approach and is focused on winning potential voters and interest groups through quick wins by increased coverage in the media of possible failures that are not only adds to this.

\section{Methodology}

This paper aims at exploring and discussing a urban regeneration pilot program as a social innovation one, using a qualitative content analysis as a text interpretation method in case study analysis. The method used as a qualitative research method is document analysis from: specialized reports, projects/study cases, databases and publications. The case study analyzed in this article is a description of a real administrative issue, with direct influence on the decision to make a solution to it. This will respond to the question that can an urban regeneration project be considered social innovation?

\section{Results and discussions}

The main purpose of social innovation in the urban regeneration of the Ferentari neighborhood is not the profit: social innovation consists of innovative activities and services motivated by the purpose of responding to a social need, disseminated through organizations, individuals or enterprises whose main purpose is social. Dissemination and adoption of solutions are necessary to define this solution as social innovation.

The objective of urban regeneration of the Ferentari neighborhood is to reduce the number of people at risk of poverty and social exclusion, along with improving the quality of life, increasing social cohesion, improving the living environment and economic growth of the neighborhood.

The pilot urban regeneration project of the Ferentari neighborhood aims to implement a new urban development model integrated in Romania with a focus on social issues. The Ferentari neighborhood is a marginalized urban area that has accumulated disadvantages from the perspective of human capital, employment 
and housing. This is a poorly socially isolated area, considered a true social exclusion bag that concentrates people with low levels of human capital, low levels of occupancy in the formal sector and poor living conditions, true outbreaks of infection, ignored mostly by the authorities. The strong stigma associated with this area, in addition to the lack or poor quality of services, drastically reduces the chances of the population to get rid of poverty.

The main issues of the Ferentari neighborhood are poor housing conditions, poor technical infrastructure, lack of identity papers, a large number of people living without legal forms, low level of training leading to low access to the labor market, lack of workplaces and lack of medical insurance. The Ferentari Urban Regeneration Project aims, among other things, to increase the quality of living and public space, to solve problems related to the absence of identity documents, to obtain various forms of social assistance and to facilitate access to the labor market, to improve the health of the population, social inclusion of young people, enhancing school performance, reducing school dropout rates and improving self-esteem among children and young people in the area.

Sustainable development involves meeting the needs of the present without compromising the ability of future generations to meet their own needs. In order for its development to be sustainable, it must take into account the social and environmental factors, to assess the long-term consequences. The integrated assessment methodologies for urban regeneration proposals are guided by the belief that sustainability requires the simultaneous fulfillment of the three criteria: economic, social and environmental. Criteria: Society, Economics, Ecology are defined by six parameters, qualitative or quantitative, contributing to the sustainability of the project and represented by a cartogram called the sustainability circle. Social innovation through the urban regeneration process of the Ferentari neighborhood, defined by the three criteria, can improve the lives of citizens. At the Societal level, public spaces are being recovered and new ones are created, transforming the geothermal areas into promenade areas of interest, providing an urban climate that diminishes the enclaves' tendencies, demolishes the blocked blocks and promotes building new condominiums in trying to change the social structure through conflict management and social integration measures. It also preserves the cultural identity of the neighborhood by capitalizing on toponymy, cultural and historical landmarks by using the cultural resources specific to the area as a means of agglutinating society, through the development of a sense of belonging to the community by promoting local values. Applying regeneration practices ensure accessibility and mobility by equipping all buildings belonging to the public domain with access ramps, so that accessibility is also easy for people with physical disabilities and identifying the areas where there are blind people by mounting traffic signs indicating this in order to reduce speed and avoid accidents.

From the economic point of view, it is meant to encourage economic activities and to promote their diversification by supporting the activities of the Roma population, promoting the traditions of the area, ensuring sustainable investments, using local human resources and ensuring housing diversification by 
setting up a multicultural center where traditional handicrafts specific to Roma people will be carried out. The Ecology Criteria is to ensure a sustainable transport system, to promote measures to improve green areas, to use solutions for environmental protection and to promote integrated waste management. All this aims at disseminating the cause-effect phenomenon between clean and healthy living environment, the insertion of renewable energy resources, increasing energy efficiency and intelligent waste management and storing them underground through buried platforms for selective collection to improve appearance and quality of the environment.

\begin{tabular}{ll}
\multicolumn{1}{c}{ Current situation } & \\
\cline { 2 - 2 } People at risk of poverty & Improving self-esteem \\
Social exclusion & Social integration \\
Unhealthy living conditions & Good quality of living \\
Poor technical-urban infrastructure & Diminishing the tendency to enclaves \\
Lack of identity documents & Ensuring accessibility and mobility \\
People who live without legal forms & Obtaining legal forms \\
Low level of training & Reduction the rate of dropout \\
Low access to the labor market & Facilitating access to the labor market \\
Lack of jobs & Providing sustainable investment \\
Lack of medical insurance & Getting different forms of social assistance
\end{tabular}

Figure 1. Actions for social change

\section{Drivers and barriers related to this project}

According to Torfing and Sörensen (2011), the lack of competition in the market explains to a certain extent limited innovation in the public sector. Competition is the manifestation of the economy on the market. This implies the liberalization of regulations that undermine free trade in various service areas. From this point of view, there is a need for increasing competition of public services with private initiatives. Public procurement programs (the process by which public authorities, such as government departments or local authorities, acquire goods or services from companies) have led to this competitor's incentive, but have resulted in a wrong perception of consumers in terms of expectations they are rated as very large especially when they have several variants. In terms of choosing a place to live and work, regions and cities show great competition, and to enhance attractiveness, local and regional authorities use service quality as a competitive advantage.

I believe that the two desires: to improve the quality of public services, and the desire to reduce bureaucracy, has become a political issue, being negotiated among political parties. It represents an incentive for the public sector to innovate. In literature it is called "political competition", where authors like Walker (2006) and Bekkers (2011) consider that this political competition for the consent of citizens who have increasingly higher expectations and demands represents a huge opportunity to innovate. 
A very important factor which can support or hinder innovation is leadership, both administrative and political. "Linking leadership" refers to connecting the political realm with the innovation project by linking people, ideas and resources.

Innovation is a risky process itself, because the results are almost always unknown. While Drucker (1985) highlights the importance of innovation and entrepreneurship through the development of organizations in the long term, goaloriented and a systematic perspective on the use of resources, we find barriers that prevent the process. We speak about lack of harmonization between the legislation regulating the implementation of structural instruments and other relevant national legislative acts, complex administrative procedures, lack of administrative capacity both at the level of the managing authorities and among the beneficiaries, low level of response of local authorities in the process of solving the problems faced by Roma and other disadvantaged communities, lack of co-financing capacity of local authorities and unequal distribution of tasks among ministries and other public entities at national level.

Social innovation is characterized not only by the problems it seeks to solve and the results it achieves, but also by its process and methods.

The practices outlined above can form a social innovation model, with well-implemented primary elements, that can generate social change.

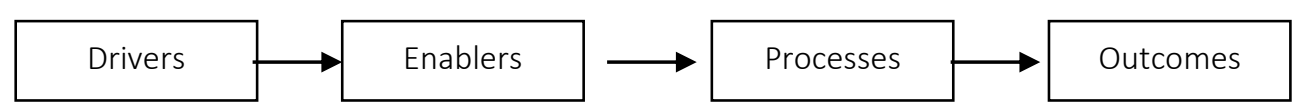

Figure 2. Model of social innovation through urban regeneration Source: adaptation after Lauren O'Byrne, Michael Miller, Ciara Douse, Rupa Venkatesh, Naim Kapucu ,Social Innovation in the Public Sector: The Case of Seoul Metropolitan Government

The outcomes of social innovation through urban regeneration will take form after being implemented the pilot program and will increase the quality of housing, reduce the number of people at risk of poverty, contribute to increasing social cohesion by solving the urban problems of the area.

\section{References}

Adams, D. \& Hess, M., 2008. Social Innovation as a new public administration strategy. Proceedings of the 12th annual conference of the international Research Society for Public Management March 2008.

Albury, D., 2005. Fostering Innovation in Public Services. Public Money \& Management, Vol. 25, No. 1, pp. 51-56.

Bekkers, V., et al., 2011. Innovation in the public sector: linking capacity and leadership.Houndsmills: Palgrave McMillan; 3-32. 
Borins, S., 2008. Innovations in Government: Research recognition and replication. Washington: Brookings Institute; 28-52.

Borins, S., 1998. Innovating with Integrity, Georgetown University Press, Washington, DC.

Cooperrider, D.L., Pasmore, W.A., 1991.Global social change: a new agenda for social science?.Human Relations, Vol 44, No 10.

Drucker, P. F., 1985. Innovation and entrepreneurship: Practice and principles. New York: Harper \& Row.

Evans, G., 2009. Creative cities, creative spaces and urban policy. Urban Studies, 46, 1003-1040.

Gabor, D., 1970. Innovations: scientific, technological, and social. London: Oxford University Press.

Kelman, S., 2008. New Public Management in Europe. Houndsmills: Palgrave McMillan, 26-51.

Langlois, S., 2002. Nouvelles orientations en sociologie de la consommation. L'Année sociologique, numéro 1, S. 83-104.

Mulgan, G., Tucker, S., Rushanara; A., Ben., 2011. Social innovation: what it is, why it matters and how it can be accelerated. Skollcentre for social entrepreneurship. Saïd Business School. University of Oxford.

O’Byrne, L., Miller, M., Douse, C., Venkatesh, R. and Kapucu, N., 2014. Social innovation in the public sector: The case of Seoul Metropolitan Government. Journal of Economic and Social Studies, 4(1):53-71.

Porter, L., \& Shaw, K. (Eds)., 2013. Whose urban renaissance?: An international comparison of urban regeneration strategies. London: Routledge.

Roberts, P., \& Sykes, H. (Eds.)., 2000. Urban regeneration: A handbook. London: Sage Publications.

Sassen, S., 2007, "Seeing Like a City", in Burdett, R. (Ed.) The Endless City, Phaidon, London, UK

Sörensen, E. \& Torfing, J., 2011. Enhancing collaborative innovation in the public sector. Administration \& Society, 43(8); 842-868.

Walker, R., 2006. Innovation type and diffusion: an empirical analysis of local government. Public Administration, 84(2); 311-335.

Walters, J., 2001. Understanding Innovation: What Inspires It? What Makes It Successful? PricewaterhouseCoopers Endowment for the Business of Government, Arlington, VA. 